\title{
Fungichromin Production by Streptomyces padanus PMS-702 for Controlling Cucumber Downy Mildew
}

\author{
Ya-Ting Fan ${ }^{1}$, Kuang-Ren Chung $\mathbb{B}^{1 *}$, and Jenn-Wen Huang $\mathbb{B}^{1,2 *}$ \\ ${ }^{1}$ Department of Plant Pathology, National Chung-Hsing University (NCHU), Taichung 40227, Taiwan \\ ${ }^{2}$ Innovation and Development Center of Sustainable Agriculture (IDCSA), NCHU Taichung 40227, Taiwan
}

(Received on March 18, 2019; Revised on April 23, 2019; Accepted on May 12, 2019)

Streptomyces padanus PMS-702 strain produces a polyene macrolide antibiotic fungichromin and displays antagonistic activities against many phytopathogenic fungi. In the present study, experimental formulations were assessed to improve the production of fungichromin, the efficacy of PMS-702 on the suppression of sporangial germination, and the reduction of cucumber downy mildew caused by Pseudoperonospora cubensis. PMS-702 strain cultured in a soybean meal-glucose (SMG) medium led to low levels of fungichromin accumulation and sporangial germination suppression. Increasing medium compositions and adding plant oils (noticeably coconut oil) in SMG significantly increased fungichromin production from 68 to $1,999.6 \mu \mathrm{g} / \mathrm{ml}$. Microscopic examination reveals that the resultant suspensions significantly reduced sporangial germination and caused cytoplasmic aggregation. Greenhouse trials reveal that the application of PMS-702 cultural suspensions reduced downy mildew severity considerably. The addition of Tween 80 into the synthetic medium while culturing PMS-702 further increased the suppressive

\footnotetext{
*Co-corresponding authors.

Kuang-Ren Chung

Phone) +886-4-2284-0780 ext. 301, FAX) +886-4-2287-7585

E-mail)krchung@nchu.edu.tw

ORCID

https://orcid.org/0000-0002-2640-2951

Jenn-Wen Huang

Phone) +886-4-2284-0780 ext. 351, FAX) +886-4-2287-7585

E-mail)jwhuang@dragon.nchu.edu.tw

https://orcid.org/0000-0003-0798-4332

(c) This is an Open Access article distributed under the terms of the Creative Commons Attribution Non-Commercial License (http:// creativecommons.org/licenses/by-nc/4.0) which permits unrestricted noncommercial use, distribution, and reproduction in any medium, provided the original work is properly cited.
}

Articles can be freely viewed online at www.ppjonline.org. efficacy of downy mildew severity, particularly when applied at $24 \mathrm{~h}$ before inoculation or co-applied with inoculum. Fungichromin at $50 \mu \mathrm{g} / \mathrm{ml}$ induced phytotoxicity showing minor necrosis surrounded with light yellowish halos on cucumber leaves. The concentration that leads to $90 \%$ inhibition (IC90) of sporangial germination was estimated to be around $10 \mu \mathrm{g} / \mathrm{ml}$. The results provide a strong possibility of using the $S$. padanus PMS-702 strain as a biocontrol agent to control other plant pathogens.

Keywords : bioformulation, biological control agent, polyene macrolide antibiotic, Pseudoperonospora cubensis, Streptomyces padanus

Handling Editor : Sang, Mee Kyung

Cucumber (Cucumis sativus L.) is one of the most important crops worldwide. Many diseases can affect cucumber. Of them, downy mildew caused by Pseudoperonospora cubensis (Berk. Et Curt.) Rostov. has been reported to cause severe economic loss in cucurbits in many countries (Thomas, 1996). P. cubensis is an obligate parasite classified in the Class of Oomycetes. The pathogen produces sporangia, which either directly germinate or produce zoospores in the presence of free water on the surface of leaves. Zoospore becomes encysted upon sensing the location of stomata and forms a germ tube, which could enter the host plant through the stomata (Lebeda and Cohen, 2011). Hyphae grow intercellularly and form haustoria to adsorb nutrients from host cells. On the underside of leaves, the pathogen produces fuzzy, gray to black sporangia, which can be dispersed by wind. $P$. cubensis can be transmitted through seeds as well (Cohen et al., 2014). The pathogen rarely produces oospores and the role of oospores in the life cycle of $P$. cubensis remains largely unknown. 
P. cubensis induces yellow to brown angular spots, which may intermingle to form large lesions (Savory et al., 2011). Under favorable conditions, $P$. cubensis infection on cucumber could result in plant death if uncontrolled (Palti and Cohen, 1980).

Fungicides are commonly used to control cucumber downy mildew in commercial farms. However, there is an increasing concern about the adverse effects of fungicides on the environment and food safety. The use of biological control for the management of plant diseases has become more demanding. Frequent use of fungicides also poses an increased risk on the induction of resistant strains. $P$. cubensis has been reported to develop resistance to various fungicides including: metalaxyl, mancozeb, and strobulurin (Heaney et al., 2000; Reuveni et al., 1980; Russell, 2002; Thomas and Jourdain, 1992). Fungicides could impact non-target or beneficial microorganisms, altering ecological balance that is required for the agricultural sustainability. Breeding cucumber cultivars resistant to $P$. cubensis is time-consuming. Even though cucumber cultivars with resistance to $P$. cubensis are available, the resistance can be broken down over time if the pathogen develops a new race (Holmes et al., 2004).

Biological control is an idea alternative for organic farming because the practice is less harmful. Streptomyces spp. are often used as biocontrol agents because they can produce a wide array of secondary metabolites (Bubici, 2018; Chen et al., 2016; Yuan and Crawford, 1995). Streptomyces spp. are Gram positive bacteria commonly found in soil and rhizosphere. S. lydicus WYEC 108 and S. griseoviridis $\mathrm{K} 61$ have been commercialized as plant protection agents. S. lydicus WYEC 108 is registered under the brand name Actinovate (Yuan and Crawford, 1995) to suppress and control several foliar diseases including downy mildew. In addition, Bacillus subtilis QST713 (Serenade) and Saccharomyces cerevisiae LAS117 cell walls (Romeo) are two biocontrol products registered to control downy mildew of various vegetables. S. padanus PMS-702 was originally isolated from spent forest mushroom compost and has been characterized to be antagonistic against a wide range of plant pathogenic fungi and fungus-like microorganisms, including Rhizoctonia solani AG-4, Alternaria brassicicola, Botrytis cinerea, Colletotrichum gloeosporioides, several Fusarium spp., Pythium aphanidermatum, and Phytophthora spp. (Shih, 2003). The key ingredient in PMS-702 cultural suspensions responsible for toxicity to $R$. solani AG-4 is fungichromin based on NMR and mass spectral analyses (Shih et al., 2003). Fungichromin, also called pentamycin, is a polyene macrolide antibiotic. Many Streptomyces and related species have been reported to produce fungichromin. Those include $S$. cellulose, S. fradiae, S. griseus, S. roseoluteus, and Streptoverticillium cinnamomeum subsp. cinnamomeum (Harrison et al., 1986; Raatikainen et al., 1993; Robison et al., 1971). The minimal inhibitory concentration (over $90 \%$ inhibition) to $R$. solani AG-4 is around $72 \mu \mathrm{g} / \mathrm{ml}$ (Shih et al., 2003). Polyene macrolide antibiotics affects membrane-bound ergosterol, resulting in ion leakage and cell death (Baginski et al., 2006).

The inhibitory efficacy of $S$. padanus PMS-702 against plant pathogenic fungi is strongly correlated with the amount of fungichromin. Thus, increasing the production of fungichromin has practical applications for using PMS702 as a biocontrol agent. The production of fungichromin by PMS-702 could be enhanced to the levels ranging from 112 to $549 \mu \mathrm{g} / \mathrm{ml}$ by increasing nutrients and adding oleic acid (Huang et al., 2007; Wu et al., 2006; Zang et al., 2011). In the present study, fermentation processes were optimized to improve the production of fungichromin by nearly 30 -fold reaching $1999.6 \mu \mathrm{g} / \mathrm{ml}$. Coconut oil was found to be one of the most effective elements to enhance the production of fungichromin. PMS-702 cultural suspensions effectively suppressed the germination of sporangia produced by $P$. cubensis and downy mildew severity on cucumber both in detached-leaf assays and pot-experiments.

\section{Materials and Methods}

Microorganisms and cultural conditions. P. cubensis was isolated from a diseased leaf of field-grown cucumber. The identity of $P$. cubensis was determined based on morphology and by sequence analysis of a $\beta$-tubulin gene fragment, which was amplified by PCR with the primers BTub-F and BTub-R as described by Quesada-Ocampo et al. (2012). DNA was extracted and purified using a Plant Genomic DNA purification kit (Taipei, Taiwan). DNA fragments were directly sequenced using an Applied Biosystem 3730 DNA analyzer at Tri-Biotech (Taipei, Taiwan). Sequence similarity search was performed against the National Center for Biotechnology Information (NCBI) database using the BLASTX program. P.cubensis was inoculated on cucumber leaves and the inoculated plants were maintained in a greenhouse located in the National Chung Hsing University (Taichung, Taiwan). Seeds of cucumber cv. Xiu Yan and cv. Honey Yan were purchased from Known-You Seed (Kaohsiung, Taiwan). Every 3 weeks, seeds were sterilized in $1 \%$ Clorox for $30 \mathrm{~min}$, rinsed 5 times with sterile water, placed in a petri dish with $20 \mathrm{ml}$ sterile water, and incubated at $28^{\circ} \mathrm{C}$ for 2 days. Germinated seeds were planted in a peat moss (Sondermischung GRAMOGLOR, Germany) in a plastic tray $(50 \mathrm{~cm}$ 
$\times 30 \mathrm{~cm} \times 6.5 \mathrm{~cm})$. Cucumber plants $(\sim 3$ weeks old $)$ were inoculated by spraying with sporangial suspensions $(5 \times$ $10^{2}$ sporangia $/ \mathrm{ml}$ ) and maintained in a greenhouse.

S. padanus PMS-702 was originally isolated from spent forest mushroom compost and has been previously characterized (Shih et al., 2003). S. padanus was cultured on a Bacto ISP4 medium (Difco) for 7 days at $30^{\circ} \mathrm{C}$. Bacterial cells were washed off with $0.05 \%$ Tween 20 solution and the concentration was adjusted to $4 \times 10^{8} \mathrm{cfu} / \mathrm{ml}$ (O.D. $=$ $\sim 1.08$ at $620 \mathrm{~nm})$. Bacterial suspensions $(1 \mathrm{ml})$ were added into $99 \mathrm{ml}$ of soybean meal-glucose (SMG) basal medium containing $0.5 \%$ soybean meal, $0.5 \%$ glucose and $0.04 \%$ $\mathrm{CaCO}_{3}$ (Shih et al., 2003) and incubated for additional 5 days on a rotary shaker set at $128 \mathrm{rpm}$ for the production of fungichromin. A modified soybean meal-glucose (SMGM) medium containing $1.12 \%$ soybean meal, $1.12 \%$ glucose and $0.046 \% \mathrm{CaCO}_{3}$ (Zang et al., 2011) was also used to culture PMS-702 for the production of fungichromin. Plant oil was added into SMG, autoclaved, and used for the production of fungichromin by PMS-702. Plant oils $(0.5,1$, or $2 \%)$ used in this study included: sunflower oil (Uni-President Enterprises, Tainan, Taiwan), ben oil (also known as Malunggay oil) (Shopee Philippines), and corn oil (Yuan Shan Food, Yuanlin, Taiwan), and coconut oil (CocoLicious, Philippines). PMS-702 grown in SMG broth formed sticky substances (containing fungichromin and bacteria) aggregating on the surface of the medium along the wall of the Erlenmeyer flask. After a 3-day incubation, sticky substances were scraped off with a sterile spatula, mixed with medium, and incubated for additional 2 days to make SMG-C-2.

Assays for sporangial germination. Cultural suspensions of $S$. padanus PMS-702 were mixed with equal volume of sporangia $\left(10^{4}\right.$ sporangia $\left./ \mathrm{ml}\right)$ and incubated at $20^{\circ} \mathrm{C}$ in the dark. After a 2-h incubation, $10 \mu \mathrm{l}$ suspensions were placed on a glass depression slide and observed using a Nikon/ ECL. E400 microscope (Tokyo, Japan) $(\times 40$ magnification) after staining with cotton blue solution. For each treatment, 50 randomly selected sporangia were examined. Each treatment contained at least 3 replicates. Percentage (\%) of inhibition was calculated by dividing the relative difference of the number of sporangial germination between mock control and treatment by the number of sporangial germination of the control and multiplied by 100 .

Purification and quantification of fungichromin. Fungichromin was extracted from 5-day-old bacterial cultures by mixing with equal volume of ethyl acetate in a $250 \mathrm{ml}$ flask. The mixture was sonicated for $15 \mathrm{~min}$ and incubated at $28^{\circ} \mathrm{C}$ for $4 \mathrm{~h}$ on a rotary shaker set at $100 \mathrm{rpm}$. The organic extracts (upper layer) were collected and analyzed by a PU-780 high performance liquid chromatography (HPLC) (Jasco, Tokyo, Japan). Samples were separated in a HYPERSIL BDS C-18 column (Thermo Scientific, Göteborg, Sweden) at $28^{\circ} \mathrm{C}$ using $60 \%$ acetonitrile as a mobile phase with flow rate set at $0.5 \mathrm{ml} / \mathrm{min}$ as described (Wu et al., 2008; Zang et al., 2011). Fungichromin was detected by a UV-970 detector (Jasco) at $357 \mathrm{~nm}$ wavelength. Fungichromin was quantified using a regression line generated from a commercially available standard (Sinon Corp., Taichung, Taiwan) dissolved in dimethyl sulfoxide (DMSO).

Preparation of inoculum and plant inoculation. Cucumber plants (cv. Xiu Yan or cv. Honey Yan) were prepared as described above. Before inoculation, healthy cucumber leaves were sterilized with $15 \mathrm{X}$ Clorox containing $2 \%$ Tween 20 for $8 \mathrm{sec}$. After rinsing 2 times with sterile water, leaves were dried on a paper towel, and placed on a filter paper with the underside of the leaf facing up in a moist petri dish. Leaf stalk was wrapped with sterile moist cotton to maintain vigor. P. cubensis inoculum was prepared by washing off sporangia from diseased leaves with sterile water to make an appropriate concentration. For spot inoculation, sporangial suspensions $\left(5 \times 10^{2}\right.$ sporangia/ml $)$ were placed by dropping $10 \mu \mathrm{l}$ on detached cucumber leaves. To test the effect of PMS-702 suspensions on sporangial germination, cultural suspensions $(10 \mu \mathrm{l})$ were first placed on a detached leaf and sporangia were placed on the same spot. Leaves treated with sterile water and inoculated with sporangia were used as mock controls. The treated leaves were incubated at $20^{\circ} \mathrm{C}$ in an incubator with $12 \mathrm{~h}$ daily illumination for lesion development 7 days after inoculation (dai).

For spray inoculation, sporangia $\left(0.5 \mathrm{ml}, 10^{4}\right.$ sporangia/ $\mathrm{ml}$ ) and PMS-702 cultural suspensions at an appropriate concentration ( 0.5 or $1 \mathrm{ml}$ in $100 \mathrm{ml}$ water) were individually (co-inoculation or $24 \mathrm{~h}$ before or after inoculation) sprayed onto detached leaves or the $2^{\text {nd }}$ true leaf of the plant using a mini-sprayer. The inoculated plants were bagged for 2 days and maintained in a greenhouse after bag removal. Downy mildew severity was examined 7 dai. Disease severity was calculated using the following scale: 0 , no lesions; 1 , lesion areas $0-3 \%$; 2 , lesion areas 3-6\%; 3, lesion areas $6-12 \%$; 4 , lesion areas $12-25 \%$; and 5 , lesion areas $25-50 \%$; 6 , lesion areas $50-75 \%$; 7 , lesion areas $75-87 \%$; 8 , lesion areas $87-100 \%$; and 9, lesion areas $100 \%$ (Jenkins 1983; Michereff et al., 2009). Disease severity was determined by the following formula: Disease severity $(\%)=[\Sigma$ (disease index $\times$ number of infected leaves)/(total number 
of leaves $) \times 9] \times 100$.

To test the effect of fungichromin on the sporangial germination on detached cucumber leaves, sporangia $\left(10^{3}\right.$ spores $/ \mathrm{ml}$ ) were mixed with equal volume of fungichro$\min (2,10,20,50$ or $100 \mu \mathrm{g} / \mathrm{ml})$ dissolved in DMSO and placed on the underside of cucumber leaves. To test the effect of fungichromin on downy mildew severity, cucumber leaves were sprayed with fungichromin and inoculated with sporangia. The treated leaves or plants were incubated in a moist incubator equipped with $12 \mathrm{~h}$ daily illumination. Disease incidence was recorded 7 dai.

Statistical analysis. Each treatment contained at least three replicates and experiments were conducted at least three times. Data were analyzed by ANOVA or regression using SAS/STAT software version 9.0 (SAS Institute, Cary, NC, USA). Significance of treatments was determined using Fisher's least significant difference test $(P \leq 0.05)$.

\section{Results}

S. padanus PMS-702 suppresses sporangial germination of $\boldsymbol{P}$. cubensis. A 10-fold dilution of cultural suspensions prepared from $S$. padanus PMS-702 cultured in a soybean meal-glucose (SMG) basal medium for 3 days suppressed sporangial germination of $P$. cubensis (Fig. 1A). Prolonged incubation slightly but not significantly enhanced the suppressive effectiveness. At a 20 or 50-fold dilution, cultural suspensions of PMS-702 had no inhibitory effect. The addition of ben oil, corn oil, coconut oil but not sunflower oil into SMG significantly increased the inhibitory effect on sporangial germination (Fig. 1B). Increasing the concentration of coconut oil or corn oil significantly increased the inhibitory efficacy (Fig. 1C).

Sticky substances increase the suppressive effectiveness of PMS-702 on sporangial development. SMG amended with plant oil (sunflower oil, ben oil, corn oil, or coconut oil) failed to suppress sporangial germination in the absence of PMS-702 (data not shown). PMS-702 cultured in SMG amended with 1\% coconut oil (designated SMG-C-1) resulted in a strong inhibition on sporangial germination at a 100-fold dilution (Fig. 2A). However, no inhibitory effect was observed at a 200-fold dilution. PMS-702 grown in SMG-C-1 broth formed sticky substances (containing fungichromin and bacteria) aggregating on the surface of medium along the wall of the Erlenmeyer flask. After PMS-702 was incubated for 3 days, sticky substances were scraped off with a sterile spatula, mixed with medium, and incubated for additional 2 days (designated SMG-C-2).
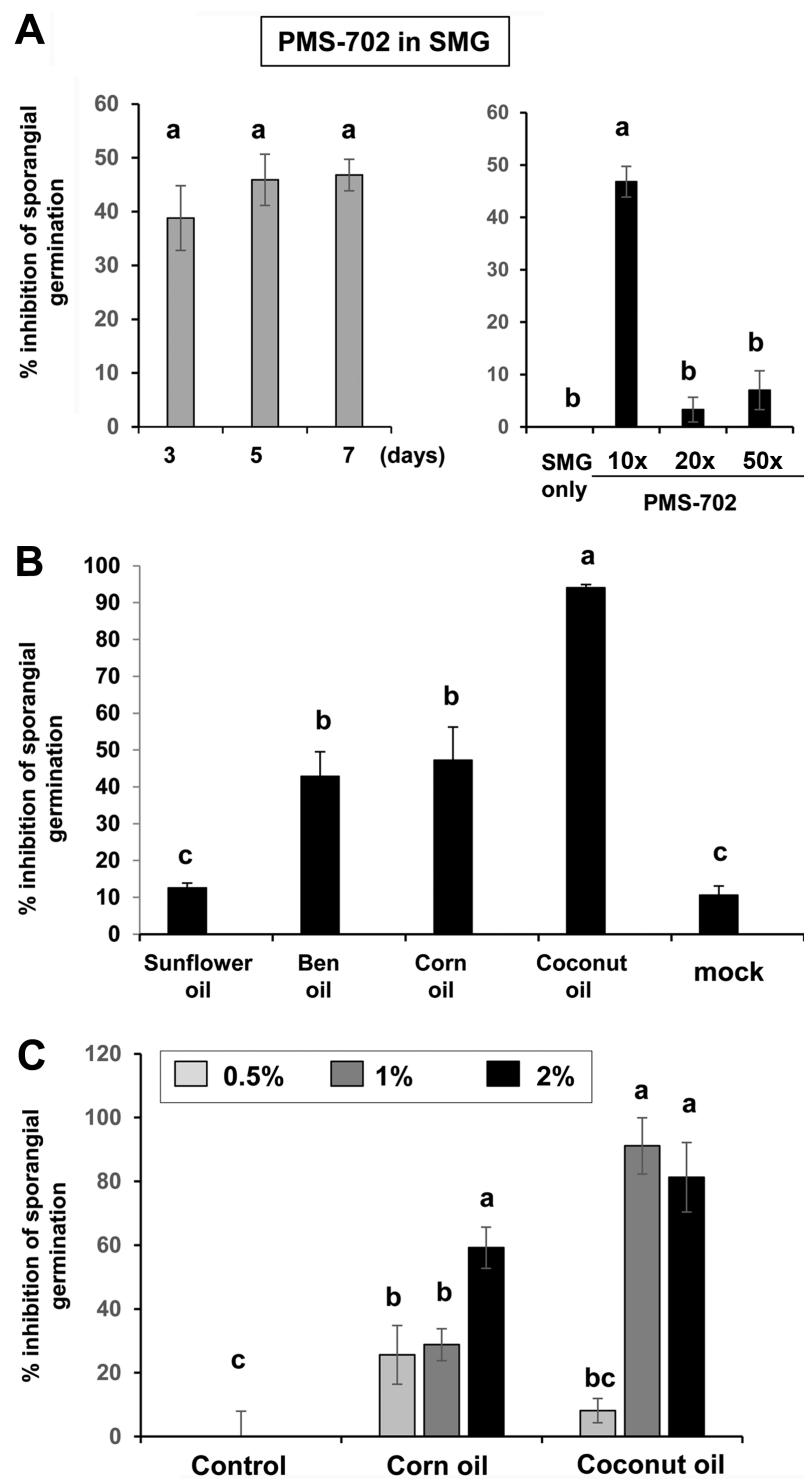

Fig. 1. Efficacy of cultural suspensions of S. padanus PMS-702 on the germination of sporangia produced by P. cubensis. (A) Dilution effects on sporangial germination. PMS-702 was cultured in soybean meal-glucose (SMG) broth for 3, 5 or 7 days. Cultural suspensions were mixed $(1: 1, \mathrm{v} / \mathrm{v})$ with sporangia $\left(10^{4}\right.$ sporangia/ $\mathrm{ml}$ ) to make $10 \times, 20 \times$ or $50 \times$ solution, and incubated at $20^{\circ} \mathrm{C}$ in the dark for $2 \mathrm{~h}$. Mock controls were treated with SMG only. (B) Effects of plant oils (1\%) on sporangial germination. (C) Concentration effects of corn oil and coconut oil on sporangial germination. PMS-702 was cultured in SMG amended with or without oil for 5 days and mixed with sporangia. Cultural suspensions at a 100 -fold dilution were mixed with sporangia. In each treatment, $10 \mu \mathrm{l}$ of suspensions was placed on a glass depression slide and observed microscopically. For each treatment, 50 randomly selected sporangia were examined. Data are means of three biological replicates. Means indicated by different letters were significantly different according to the Fisher's least significance difference test $(P=0.05)$. 

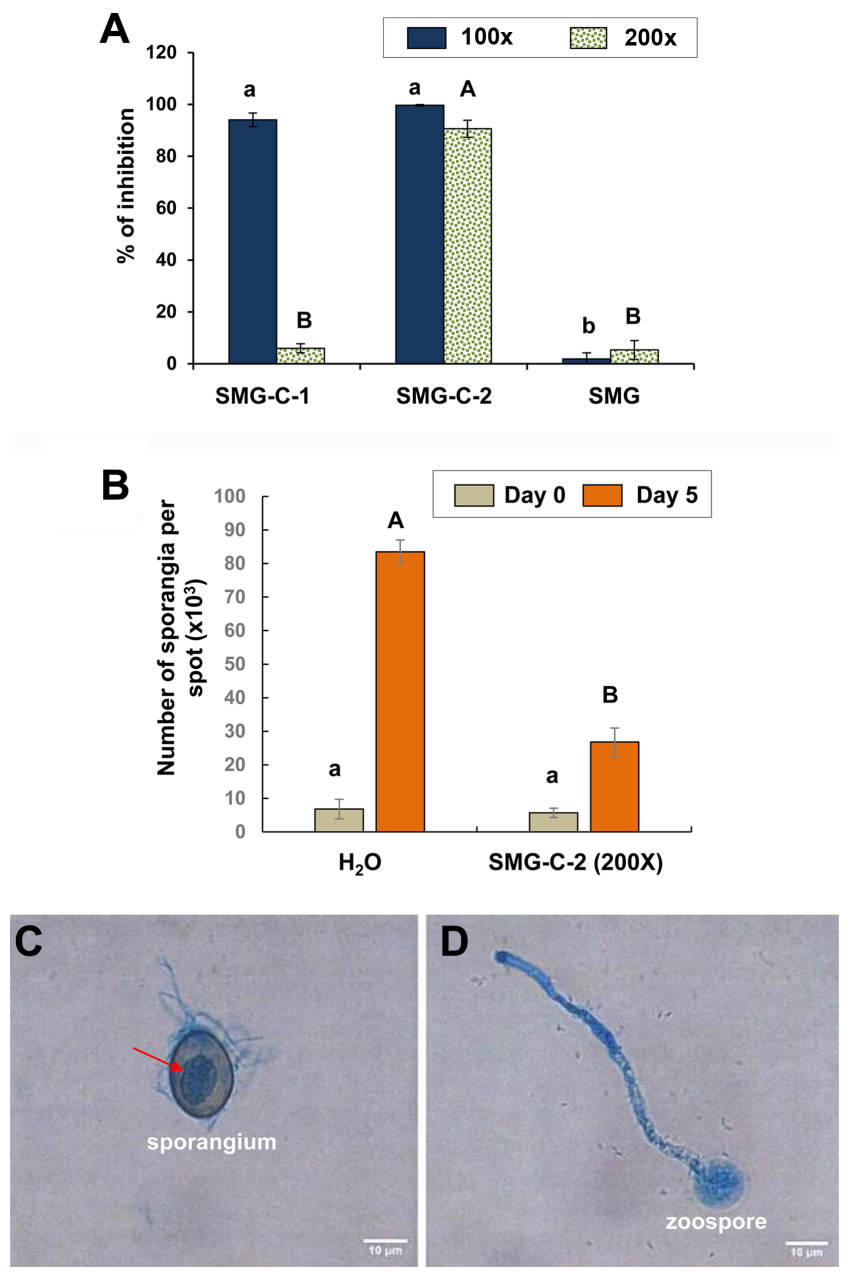

Fig. 2. Sticky substances formed by S. padanus PMS-702 increase the suppressive efficacy of germination of sporangia produced by $P$. cubensis. (A) In-vitro assays of sporangial germination. PMS-702 was cultured in soybean meal-glucose (SMG), SMG amended with $1 \%$ coconut oil (designated SMG-C-1), or SMG-C-1 containing sticky substances (SMG-C-2) for 5 days. Cultural suspensions were mixed $(1: 1, \mathrm{v} / \mathrm{v})$ with sporangia $\left(10^{4}\right.$ sporangia $/ \mathrm{ml}$ ) to make $100 \times$ or $200 \times$ solution, and incubated at $20^{\circ} \mathrm{C}$ in the dark for $2 \mathrm{~h}$. (B) In-planta assays of sporangial propagation on cucumber leaves. Spornagia treated with water (mock control) propagate quickly on cucumber leaves incrreasing 12-fold after a 5-day incubation. Sporangia treated with PMS-702 suspensions cultured in SMG-C-2 $(200 \times)$ propagate much slower than mock control after 5 dai. Data are means of three biological replicates. Means indicated by different letters were significantly different according to the Fisher's least significance difference test $(P=0.05)$. (C) Microscopic images of a sporangium treated with PMS-702 in SMG-C-2 for $24 \mathrm{~h}$ and stained with cotton blue, showing cytoplasmic aggregation (indicated by an arrow). (D) A germinating zoospore after released from a sporangium treated with water. Only reprenestatives are shown.
SMG-C-2 displayed a strong inhibitory effect on sporangial germination at either 100 - or 200 -fold dilution. SMG-C-2 cell suspensions significantly suppressed the propagation of sporangia on cucumber leaves 5 dai (Fig. 2B). Sporangia treated with SMG-C-2 cell suspensions failed to germinate or produce zoospores and showed aggregation in the cytoplasm (Fig. 2C, D).

The production of fungichromin by PMS-702 in different formulations. PMS-702 cultured in SMG basal medium produced fungichromin, reaching $\sim 68 \mu \mathrm{g} / \mathrm{ml}$ after 5 dai (Fig. 3). Scraping off sticky substances into medium increased nearly 2-fold fungichromin production. Increasing the concentrations of soybean meal (from 0.5 to $1.12 \%$ ), glucose (from 0.5 to $1.12 \%$ ), and $\mathrm{CaCO}_{3}$ (from

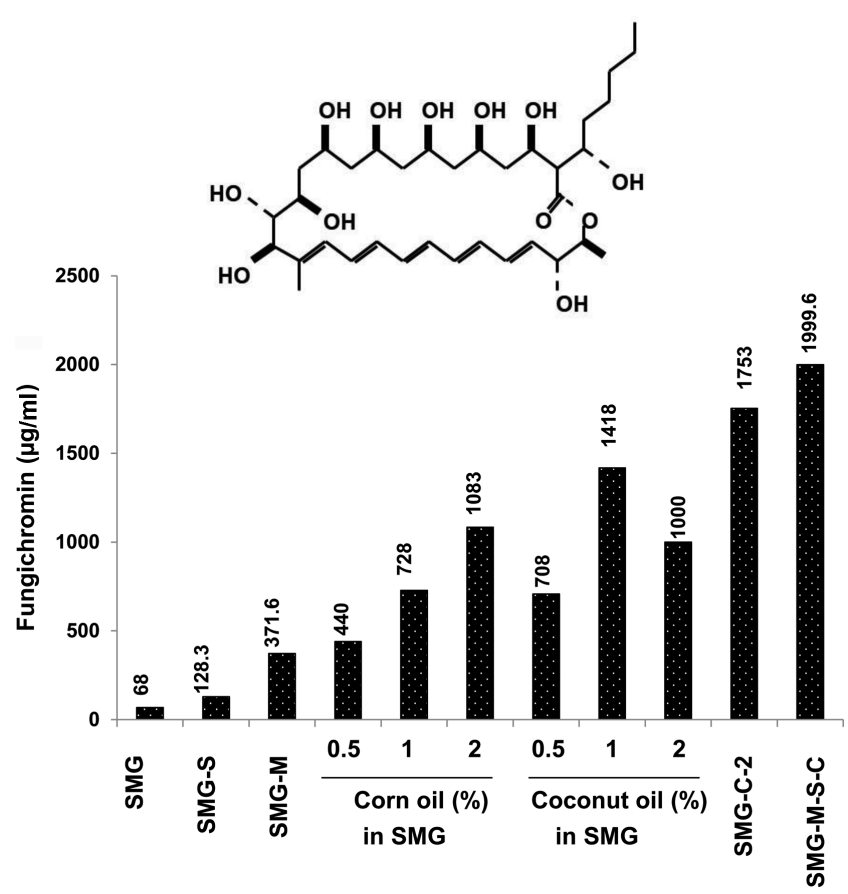

Fig. 3. Improvement of fungichromin production by S. padanus PMS-702 through different formulations. PMS-702 was cultured in soybean meal-glucose (SMG) or modified media (see below for details) as indicated at $30^{\circ} \mathrm{C}$ for 5 days. Fungichromin was extracted from cultural filtrates with ethyl acetate, separated by HPLC, and quantified using a regression line generated from a commercially available standard. Chemical structure of fungichromin is also shown.

SMG: $0.5 \%$ soybean meal, $0.5 \%$ glucose and $0.04 \% \mathrm{CaCO}_{3}$

SMG-S: SMG + sticky substances

SMG-M: $1.12 \%$ soybean meal, $1.12 \%$ glucose and $0.046 \%$ $\mathrm{CaCO}_{3}$

SMG-C-2: SMG-S + 1\% coconut oil

SMG-M-S-C: SMG-M + sticky substances $+1 \%$ coconut oil 

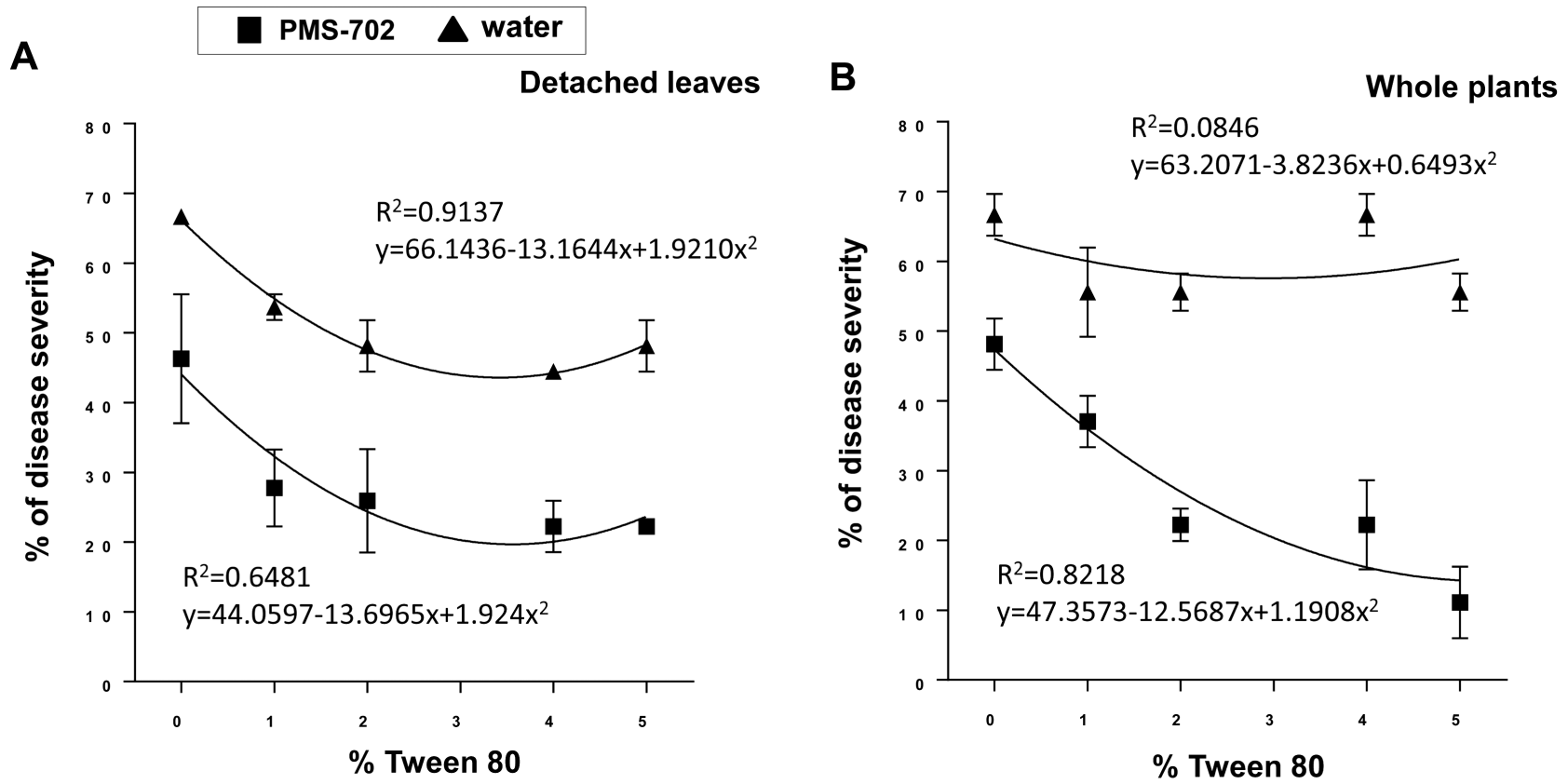

Fig. 4. Tween 80 improves the efficacy of S. padanus PMS-702 in reducing downy mildew severity on cucumber. (A) Detached leaf assays. (B) Whole plant assays. PMS-702 was cultured in soybean meal-glucose amended with 1\% coconut oil and sticky substances (SMG-C-2) amended with different concentrations of Tween 80 for 5 days and sprayed onto detached cucumber leaves, which were immediately inoculated with sporangial suspensions $\left(10^{4}\right.$ sporangia/ml $)$ of $P$. cubensis. Leaves treated with water were used as mock controls. The treated leaves were kept in a moist petri dish and the whole plants were bagged for 2 days and maintained in a greenhouse after bag removal. Downy mildew severity was examined 7 dai. Data are means of three biological replicates and treatment means separated by nonlinear regression.

0.04 to $0.046 \%$ ), designated SMG-M, increased more than 5 -fold fungichromin. The addition of corn oil in SMG increased the production of fungichromin considerably in a concentration-dependent manner, producing $1,083 \mu \mathrm{g} / \mathrm{ml}$ fungichromin (a 15.9-fold increase) at $2 \%$ corn oil. The addition of coconut oil also increased the production of fungichromin considerably but not in a concentration-dependent manner. Compared to $2 \%$, coconut oil at $1 \%$ resulted in much higher fungichromin, reaching $1,418 \mu \mathrm{g} / \mathrm{ml}$. The fungichromin level reached $1,753 \mu \mathrm{g} / \mathrm{ml}$ (a 25.8-fold increase) when PMS-702 was cultured in SMG amended with 1\% coconut oil for 3 days and incubated for 2 more days with sticky substances. A combined modification by adding $1 \%$ coconut oil and sticky substances, and increasing SMG compositions (SMG-M) resulted in $1,999.6 \mu \mathrm{g} / \mathrm{ml}$ fungichromin (a 29.4-fold increase).

PMS-702 reduces cucumber downy mildew severity. Detached cucumber leaves treated with PMS-702 cell suspensions grown in SMG-C-2 significantly developed less severe downy mildew compared to those treated with water (Fig. 4A). SMG-C-2 amended with Tween 80 alone also reduced downy mildew severity in pot-experiments. Tween $80(0.5 \%)$ alone had no toxic effects on sporangial germination (data not shown). PMS-702 cultured in SMG-C-2 amended with Tween 80 provided even greater reduction in downy mildew severity as assayed on detached cucumber leaves. Similar reduction in downy mildew severity was observed in whole-plant inoculation (Fig. 4B). Moreover, application of PMS-702 cell suspensions $24 \mathrm{~h}$ before inoculation (hbi) of $P$. cubensis or co-application of PMS702 with sporangia had superior effects on the reduction of downy mildew severity compared to those treated with PMS-702 cell suspensions $24 \mathrm{~h}$ post inoculation (hpi) (Fig. $5)$.

The toxicity of fungichromin. Fungichromin at concentrations between 2.5 and $25 \mu \mathrm{g} / \mathrm{ml}$ did not cause necrotic symptoms on cucumber leaves (Fig. 6A). However, fungichromin at $50 \mu \mathrm{g} / \mathrm{ml}$ induced minor necrosis surrounded with light yellowish halos. Fungichromin at $10 \mu \mathrm{g} / \mathrm{ml}$ or higher completely suppressed sporangial germination and the occurrence of downy mildew severity (Fig. 6B). The median inhibitory dose (IC50) of fungichromin on spo- 

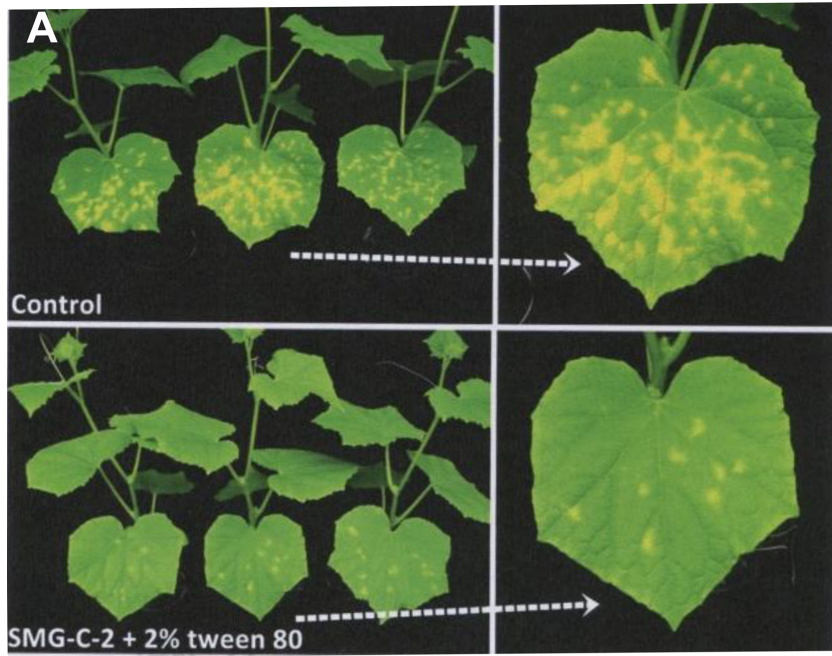

B

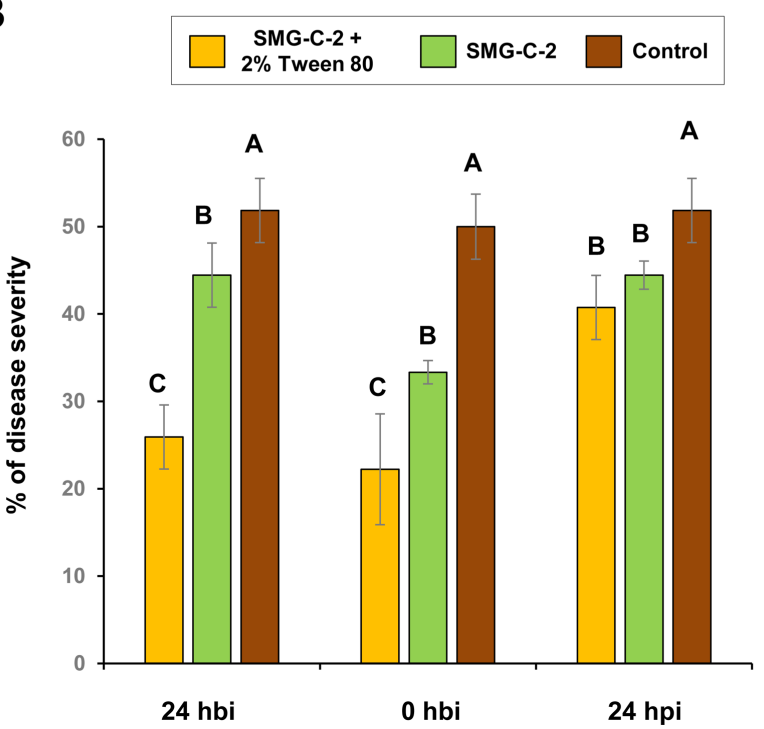

Fig. 5. Spray timing of cell suspensions of S. padanus PMS-702 for controlling downy mildew severity on cucumber leaves. (A) Cucumber leaves showing downy mildew symptoms after treated with PMS-702 suspensions cultured in SMG-C-2 amended with Twee 80 or water (control). (B) Quantification of downy mildew severity on cucumber leaves. PMS-702 was cultured in soybean meal-glucose amended with $1 \%$ coconut oil and sticky substances (SMG-C-2), with or without $2 \%$ Tween 80 for 5 days and sprayed onto 3-week-old cucumber seedlings $24 \mathrm{~h}$ before inoculation (hbi), post inoculation (hpi) or co-application (0 hbi) with sporangial suspensions $\left(10^{4}\right.$ sporangia/ml $)$ of $P$. cubensis. Plants sprayed with water were used as mock controls. The treated plants were bagged for 2 days and maintained in a greenhouse after bag removal. Downy mildew severity was examined 7 dai. Data are means of three biological replicates. Means indicated by different letters were significantly different according to the Fisher's least significance difference test $(P=0.05)$.
A

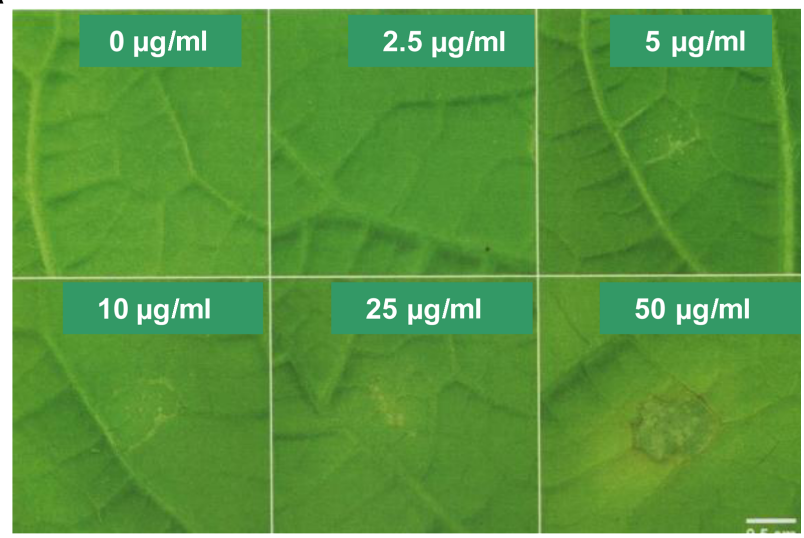

B
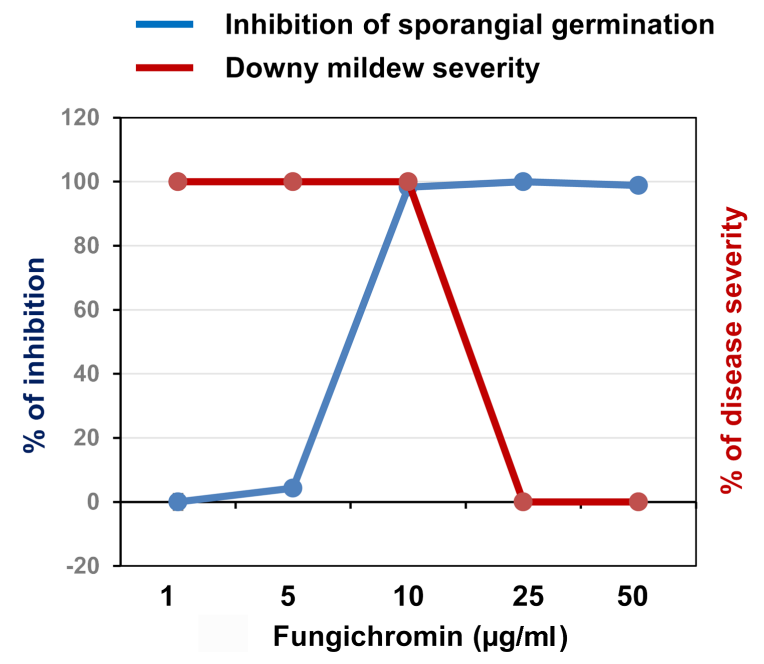

Fig. 6. Phytotoxicity of fungichromin on cucumber leaves and its effects on sporangial germination and downy mildew severity. (A) Phytotoxicity of fungichromin on detached cucumber leaves. (B) Fungichromin increases the inhibitory percentage of sporangial germination and decreases downy mildew severity on cucumber leaves. Fungichromin was dissolved in DMSO to make different concentrations and $10 \mu \mathrm{l}$ of each was placed onto cucumber leaves. To test the effect of fungichromin on downy mildew severity, cucumber leaves were sprayed with fungichromin and inoculated with sporangia. The treated leaves or plants were incubated in a moist incubator. Disease incidence was recorded 7 dai. For sporangial germination, sporangia $\left(10^{4}\right.$ sporangia $\left./ \mathrm{ml}\right)$ were mixed with fungichromin and incubated at $20^{\circ} \mathrm{C}$ in the dark. Sporangia treated with DMSO were used as mock controls. After 2-h incubation, 50 randomly selected sporangia from each of the treatments were examined microscopically.

rangial germination was estimated to be around $7.5 \mu \mathrm{g} / \mathrm{ml}$. The concentration that leads to $90 \%$ inhibition (IC90) was estimated to be around $10 \mu \mathrm{g} / \mathrm{ml}$. 


\section{Discussion}

S. padanus PMS-702 strain has been previously shown to produce fungichromin and to effectively control cabbage damping-off caused by $R$. solani (Shih et al., 2003). R. solani treated with PMS-702 cultural suspensions results in hyphal deformation and membrane damage. Fungichromin is the major component in cultural suspensions of PMS702 and may likely contribute to the reduction of $R$. damping-off. However, the effect of fungichromin on the biotrophic pathogen $P$. cubensis remains unknown. In the present study, PMS-702 was demonstrated to inhibit sporangial germination of $P$. cubensis, the causal agent of cucumber downy mildew. PMS-702 was also demonstrated to be effective for controlling cucumber downy mildew both in detached-leaf assays and pot-experiments. Importantly, fermentation processes have been fine-tuned to improve the production of fungichromin, the efficacy of PMS-702 on the suppression of sporangial germination, and the reduction of cucumber downy mildew.

PMS-702 suspensions cultured in a soybean mealglucose (SMG) basal medium effectively suppress the germination of sporangia at a 10 -fold dilution. However, after a 20-fold dilution, the inhibitory effect is nearly obliterated, indicating the presence of toxic substance, likely fungichromin. The inhibitory effect of PMS-702 cell suspensions on sporangial germination can be improved to varying degrees by adding $1 \%$ of sunflower oil, ben oil, corn oil, or coconut oil into SMG. Experiments have been carried out to demonstrate that both corn oil and coconut oil can increase the accumulation of fungichromin considerably. Plant oils have been shown to increase the production of neomycin and tylosin by the biocontrol agent $S$. fradiae (Choi et al., 1996; Ohta et al., 1995), gentamicin by Micromonospora purpurea (Choi et al., 2008), rhamnolipid by Pseudomonas SWP-4 and surfactin by Bacillus spp. (Lan et al., 2015; Makkar et al., 2011; Peng et al., 2017). It appears that adding plant oils to culture a microorganism can boost the production of secondary metabolites and increase the efficacy of biocontrol. However, the type of plant oils used to maximize the effect of secondary metabolites on pathogen inhibition and disease severity reduction shall be experimentally tested for a given biocontrol agent.

SMG amended with $1 \%$ coconut oil (SMG-C-1) at a 100 -fold dilution provides an excellent suppression on sporangial germination and greatly induces the production of fungichromin. When tested at a 200 -fold dilution, there is no inhibitory effect on sporangial germination, likely due to low levels of fungichromin. The amount of fungichromin produced by PMS-702 when grown in SMG amended with $1 \%$ coconut oil can reach $1,418 \mu \mathrm{g} / \mathrm{ml}$ (Fig. 3). After 200fold dilution, the overall concentration of fungichromin is around $7 \mu \mathrm{g} / \mathrm{ml}$, which is below the IC90 of fungichromin. When sticky substances are mixed into the culture (SMGC-2), PMS-702 suspensions greatly support fungichromin production reaching nearly $2,000 \mu \mathrm{g} / \mathrm{ml}$ and provide a strong suppression on sporangial propagation and germination even at a 200-fold dilution (Fig. 3B). Nevertheless, increasing the medium compositions and scraping off sticky substances into medium may increase bacterial population, which may lead to a higher production of fungichromin.

Fungichromin (also known as pentamycin) is a polyene macrolide antibiotic produced by many Streptomyces and related species (Harrison et al., 1986; Raatikainen et al., 1993; Robison et al., 1971). Clinically, pentamycin is often prescribed to treat vaginal candidiasis and trichomoniasis infected by protozoan parasites (Balmer, 2008). Polyene macrolide antibiotics bind to membrane ergosterol and form an ion channel, resulting in ion leakage and eventually causing cell death (Baginski et al., 2006). Because $P$. cubensis is unable to synthesize ergosterol, the mechanism of how fungichromin is toxic to $P$. cubensis remains uncertain. The toxicity of fungichromin against oomycetes could be multifaceted. Studies with amphotericin B, also a polyene macrolide, reveal that the antibiotic affects the biosynthesis of primary metabolites in oomycetes (Dória et al., 2012). Treatment of $P$. infestans with fungichromin results in aggregation within sporangia and zoospores and causes cell rupture (Shih, 2003). In the present study, microscopic observation also reveals that PMS-702 suspensions have detrimental effects on sporangial germination or zoospore production and cause aggregation in the sporangial cytoplasm in P. cubensis (Fig. 2C and D). The results demonstrate further that fungichromin is one of the major factors in PMS-702 cell suspensions contributing to inhibitory effects on sporangial germination and fungal growth.

A previous study has shown that S. padanus PMS-702 strain capable of producing fungichromin is antagonistic against $R$. solani (IC90 of $\sim 72 \mu \mathrm{g} / \mathrm{ml}$ ) (Shih et al., 2003). It appears that $P$. cubensis (IC90 of $\sim 10 \mu \mathrm{g} / \mathrm{ml}$ ) is much sensitive to fungichromin than $R$. solani, suggesting that $S$. padanus PMS-702 is a great alternative to control downy mildew diseases. In addition, fungichromin itself has low phytotoxicity to cucumber, showing minor necrosis with yellow halos when applied at $50 \mu \mathrm{g} / \mathrm{ml}$. To optimize the production of fungichromin, different formulations were tested. Experimental trials have found that a combination of increasing SMG ingredients, adding coconut oil, and including sticky substances can increase the production of 
fungichromin by nearly 30 -fold. Why the addition of coconut oil is much effective on the production of fungichromin than corn oil remains uncertain. It is tempting to speculate that the content of saturated fat might play a role. Coconut oil has the highest content of saturated fat (92\%) among plant-based oils (Eyres et al., 2016). Corn oil has $~ 13 \%$ saturated fat (Maki et al., 2018). Oils could also alter membrane permeability, serve as defoamers to reduce oxygen uptake, or function in feedback loop regulation of the biosynthetic pathway, all of which could lead to an increased production of secondary metabolites in a microorganism (Martin and McDaniel, 1977).

Tween 80 (polysorbate 80 ) mixed with SMG alone could slightly reduce downy mildew severity, consistent with the findings of Haggag (2002) and Wu et al. (2008). After culturing PMS-702, the inhibitory efficacy of Tween 80 on downy mildew increases significantly as assessed on both the whole plant and detached leaf inoculations. Tween 80 is a nonionic surfactant and emulsifier commonly used in foods, cosmetics and agricultures (Chou et al., 2005). Because fungichromin is water-insoluble, adding Tween 80 into the SMG-PMS702 formulation may likely help to release fungichromin from sticky substances and increase emulsification of fungichromin, leading to effective suppression of the test pathogen on cucumber leaves. As shown in the present study, foliar spraying of the SMGPMS702-Tween 80 formulation onto test plants $24 \mathrm{~h}$ before inoculation or co-application with inoculum is very effective to reduce downy mildew severity on cucumber. Application of cultural suspensions $24 \mathrm{~h}$ after inoculation is apparently less effective. Application of oxathiapiprolin before inoculation with $P$. cubensis effectively suppresses the release of zoospores and direct germination from sporangia, and thus reduces the size of lesions on cucumber (Cohen, 2015). Similar mechanisms may be applicable to fungichromin.

In conclusion, the current study has improved culturing conditions that can significantly enhance the production of fungichromin by the PMS-702 strain by as much as 30-fold and increase the suppressive efficacy on cucumber downy mildew severity. The formulated suspensions could be stored in the dark at $4^{\circ} \mathrm{C}$ up to 12 weeks, reducing activities only by $\sim 10 \%$. In separate studies, PMS-702 cultural suspensions have been shown to effectively reduce Pak Choi anthracnose caused by $C$. higginsianum, cabbage dampingoff caused by $R$. solani, and tomato late blight caused by $P$. infestans (Huang et al., 2007; Shih, 2003). The results obtained from the previous and present studies provide a strong possibility for using the S. padanus PMS-702 strain as a biocontrol agent in controlling diverse plant pathogens.

\section{Acknowledgments}

This research was supported by the "Innovation and Development Center of Sustainable Agriculture" under the Higher Education Sprout Project from the Ministry of Education, Taiwan, R.O.C. to JWH.

\section{References}

Baginski, M., Czub, J. and Sternal, K. 2006. Interaction of amphotericin $\mathrm{B}$ and its selected derivatives with membranes: molecular modeling studies. Chem. Rec. 6:320-332.

Balmer, J. A. 2008. Treatment of vaginal infections with intravaginal pentamycin in clinical practice. Internet. J. Gynecol. Obstet. 11:1.

Bubici, G. 2018. Streptomyces spp. as biocontrol agents against Fusarium species. CAB Rev. 13:050.

Chen, Y. Y., Chen, P. C. and Tsay, T. T. 2016. The biocontrol efficacy and antibiotic activity of Streptomyces plicatus on the oomycete Phytophthora capsici. Biol. Control 98:34-42.

Choi, D. B., Tamura, S., Park, Y. S., Okabe, M., Seriu, Y. and Takeda, S. 1996. Efficient tylosin production from Streptomyces fradiae using rapeseed oil. J. Ferment. Bioeng. 82:183186.

Choi, D. B., Park, S. S., Ahn, B. K., Lim, D. H., Lee, Y. W., Moon, J. H. and Shin, D. Y. 2008. Studies on production of gentamicin from Micromonosporas purpurea using crude vegetable oils. Proc. Biochem. 43:835-841.

Chou, D. K., Krishnamurthy, R., Randolph, T. W., Carpenter, J. F. and Manning, M. C. 2005. Effects of Tween 20 and Tween 80 on the stability of Albutropin during agitation. J. Pharm. Sci. 94:1368-1381.

Cohen, Y. 2015. The novel oomycide oxathiapiprolin inhibits all stages in the asexual life cycle of Pseudoperonospora cubensis-causal agent of cucurbit downy mildew. PLoS One 10:e0140015.

Cohen, Y., Rubin, A. E., Galperin, M., Ploch, S., Runge, F. and Thines, M. 2014. Seed transmission of Pseudoperonospora cubensis. PLoS One 9:e109766.

Dória, R. G. S., Freitas, S. H., Linardi, R. L., Mendonça, F. D., Arruda, L. P., Boabaid, F. M. and Valadão, C. A. A. 2012. Treatment of pythiosis in equine limbs using intravenous regional perfusion of amphotericin B. Vet. Surg. 41:759-765.

Eyres, L., Eyres, M. F., Chisholm, A. and Brown, R. C. 2016. Coconut oil consumption and cardiovascular risk factors in humans. Nutr. Rev. 74:267-280.

Haggag, W. M. 2002. Application of epidermal coating antitranspirants for controlling cucumber downy mildew in greenhouse. Plant Pathol. Bull. 11:69-78.

Harrison, P. H., Noguchi, H. and Vederas, J. C. 1986. Biosynthesis of polyene antibiotics: intact incorporation of 13C-labeled octanoate into fungichromin by Streptomyces cellulosae. J. Am. Chem. Soc. 108:3833-3834.

Heaney, S., Hall, A., Davies, S. and Olaya, G. 2000. Resistance 
to fungicides in the QoI-STAR cross-resistance group: current perspectives. In: Brighton Crop Protection Conference: Pests and Diseases, eds. by S. Heaney, A. Hall, S. Davies and G. Olaya, pp. 755-762. Brighton Crop Protection Council, Brighton, UK.

Holmes, G. J., Main, C. E. and Keever III, Z. T. 2004. Cucurbit downy mildew: a unique pathosystem for disease forecasting. In: Advances in Downy Mildew Research - Volume 2. Developments in Plant Pathology, eds. by P. T. N. Spencer-Phillips and M. Jeger, pp. 69-80. Springer, Dordrecht, Netherlands.

Huang, J. W., Shih, H. D., Huang, H. C. and Chung, W. C. 2007. Effect of nutrients on production of fungichromin by Streptomyces padanus PMS-702 and efficacy of control of Phytophthora infestans. Can. J. Plant Pathol. 29:261-267.

Lan, G., Fan, Q., Liu, Y., Chen, C., Li, G., Liu, Y. and Yin, X. 2015. Rhamnolipid production from waste cooking oil using Pseudomonas SWP-4. Biochem. Eng. J. 101:44-54.

Lebeda, A. and Cohen, Y. 2011. Cucurbit downy mildew (Pseudoperonospora cubensis)-biology, ecology, epidemiology, host-pathogen interaction and control. Eur. J. Plant Pathol. 129:157-192.

Makkar, R. S., Cameotra, S. S. and Banat, I. M. 2011. Advances in utilization of renewable substrates for biosurfactant production. $A M B$ Express 1:5.

Maki, K. C., Hasse, W., Dicklin, M. R., Bell, M., Buggia, M. A., Cassens, M. E. and Eren, F. 2018. Corn oil lowers plasma cholesterol compared with coconut oil in adults with abovedesirable levels of cholesterol in a randomized crossover trial. J. Nutr. 148:1556-1563.

Ohta, N., Park, Y. S., Yahiro, K. and Okabe, M. 1995. Comparison of neomycin production from Streptomyces fradiae cultivation using soybean oil as the sole carbon source in an airlift fermentor and a stirred-tank reactor. J. Ferment. Bioeng. 79:443-448.

Palti, J. and Cohen, Y. 1980. Downy mildew of cucurbits (Pseudoperonospora cubensis): The fungus and its hosts, distribution, epidemiology and control. Phytoparasitica 8:109-147.

Peng, Y. H., Chou, Y. J., Liu, Y. C., Jen, J. F., Chung, K. R. and Huang, J. W. 2017. Inhibition of cucumber Pythium dampingoff pathogen with zoosporicidal biosurfactants produced by Bacillus mycoides. J. Plant Dis. Prot. 124:481-491.

Quesada-Ocampo, L. M., Granke, L. L., Oslen, J., Gutting, H. C., Runge, F., Thines, M., Lebeda, A. and Hausbeck, M. K. 2012. The genetic structure of Pseudoperonospora cubensis populations. Plant Dis. 96:1459-1470.
Raatikainen, O., Tuomisto, J., Tahvonen, R. and Rosenqvist, H. 1993. Polyene production of antagonistic Streptomyces species isolated from Sphagnum peat. Agric. Food Sci. 2:551-560.

Reuveni, M., Eyal, H. and Cohen, Y. 1980. Development of resistance to metalaxyl in Pseudoperonospora cubensis. Plant Dis. 64:1108-1109.

Robison, R. S., Aszalos, A., Kraemer, N. and Giannini, S. M. 1971. Production of fungichromin by Streptomyces cinnamomeum subsp. cinnamomeum NRRL B-1285. J. Antibiot. 24:273.

Russell, P. E. 2002. Sensitivity baselines in fungicide resistance research and management. Crop Life International, Brussels, Belgium. 56 pp.

Savory, E. A., Granke, L. L., Quesada-Ocampo, L. M., Varbanova, M., Hausbeck, M. K. and Day, B. 2011. The cucurbit downy mildew pathogen Pseudoperonospora cubensis. Mol. Plant Pathol. 12:217-226.

Shih, H. D. 2003. Control of crop diseases with Streptomyces padanus PMS-702 and identification of fungichromin as its major antifungal metabolite related to suppress plant pathogens. Ph.D. thesis. National Chung Hsing University, Taichung, Taiwan (in Chinese).

Shih, H. D., Liu, Y. C., Hsu, F. L., Mulabagal, V., Dodda, R. and Huang, J. W. 2003. Fungichromin: a substance from Streptomyces padanus with inhibitory effects on Rhizoctonia solani. J. Agric. Food Chem. 51:95-99.

Thomas, C. E. 1996. Downy mildew. In: Compendium of cucurbit diseases, eds. by T. A. Zitter, D. L. Hopkins and C. E. Thomas, pp. 25-27. APS Press, St. Paul, MN, USA.

Thomas, C. E. and Jourdain, E. L. 1992. Host effect on selection of virulence factors affecting sporulation by Pseudoperonospora cubensis. Plant Dis. 76:905-907.

Wu, J. Y., Huang, J. W., Shih, H. D., Lin, W. C. and Liu, Y. C. 2008. Optimization of cultivation conditions for fungichromin production from Streptomyces padanus PMS-702. J. Chin. Inst. Chem. Eng. 39:67-73.

Yuan, W. M. and Crawford, D. L. 1995. Characterization of Streptomyces lydicus WYEC108 as a potential biocontrol agent against fungal root and seed rots. Appl. Environ. Microbiol. 61:3119-3128.

Zang, C. Z., Chang, Y. N., Chen, H. B., Wu, J. Y., Chen, C. I., Huang, J. W., Shih, H. D. and Liu, Y. C. 2011. Deciphering the roles of fatty acids and oils in fungichromin enhancement from Streptomyces padanus. J. Taiwan Inst. Chem. Eng. 42:413-418. 